\title{
Long-term intermittent pharmacological therapy of uterine fibroids - a possibility to avoid hysterectomy and its negative consequences
}

\author{
Anita Olejek ${ }^{1}$, Katarzyna Olszak-Wąsik ${ }^{1}$, Anna Czerwinska-Bednarska² \\ ${ }^{1}$ Department of Gynaecology, Obstetrics, and Oncological Gynaecology, Medical University of Silesia, Bytom, Poland \\ ${ }^{2}$ Gyncentrum Clinic, Katowice, Poland
}

\begin{abstract}
Uterine fibroids are found in almost $20-40 \%$ of women of reproductive age. For each woman an individualised treatment method should be applied because the hysterectomy procedure is not a good option in every case. The uterus is an organ necessary not only in reproduction. Its removal may result in: pelvic floor dysfunction and stress urinary incontinence, negative impair on life quality, depressive disorders, increased risk of cardiovascular and neurodegenerative diseases, and higher incidence of neoplastic disease. According to the last scientific reports, selective progesterone receptor modulators are the effective therapeutic option in uterine fibroids in women of reproductive age because progesterone is an important factor in their pathogenesis. Ulipristal acetate (UPA) is a progesterone receptor antagonist. It inhibits cell proliferation and angiogenesis in uterine fibroids and also reduces collagen deposits in extracellular matrix. Significant data concerning ulipristal acetate efficacy have been provided by scientific research, especially from the consecutive PEARL studies. Oral ulipristal acetate effectively and safely controls bleeding and pain in patients with symptomatic fibroids. It reduces fibroid volume and restores quality of life. The results of UPA long-term intermittent treatment are largely maintained during the off-treatment periods.
\end{abstract}

Key words: uterine fibroids, selective progesterone receptor modulator, ulipristal acetate, hysterectomy.

Uterine fibroids are the most frequent benign neoplasms of the female reproductive system. The most common complains are: abnormal and excessive uterine bleeding, pain in pelvis, dysmenorrhoea, anaemia, and infertility. Leiomyomas negatively influence the patients' quality of life [1, 2].

Uterine fibroids are found in almost $20-40 \%$ of women of reproductive age [3]. The choice of the most appropriate treatment method depends on the patient's age, pain intensity, procreative plans, and other disorders. Undoubtedly, the treatment should be individuated. For many years the uterus has been considered as an organ necessary only for reproduction. When the last pregnancy is terminated, the uterus becomes a useless and bleeding organ, causing additional negative symptoms and involving the risk of cancer [4-6].

Hence, probably in too many cases, hysterectomy was performed too hastily. Thereby, it is the second most common surgical procedure in women, after caesarean section [7].

There are many possible side effects related to the hysterectomy. However, none of them is reliably predictable in every case. Recently, the unfavourable effects of hysterectomy on pelvic floor function and other health- related disorders have been pointed out. The symptoms may occur even a few years after the hysterectomy and relevantly impair the life quality. For example, there is an increased risk of stress urinary incontinence, which typically develops 10 years after the surgical intervention. No less important is the fact that the uterus is regarded also as a sexual organ, a source of vitality and energy. It is associated with youth and desirability. Consequently, removal of the uterus may result in depressive disorders [8-11].

Swedish studies revealed that hysterectomy before the age of 50 entails increased risk of cardiovascular diseases in proceeding years. The hazard for coronary disease events and stroke is then raised $[12,13]$. Even if adnexectomy is not performed, hysterectomy influences the function of the ovaries and contributes to premature menopause. Lack of ovarian hormones is associated with higher risk of dementia [14-17]. Hysterectomy performed before a natural menopause carries a potential increased risk for neurodegenerative diseases (Alzheimer's disease, Parkinson's disease). This is due to the higher ferritin iron concentration in brain tissue as a result of uterus removal [18]. 
The incidence of neoplastic disease among women who have had hysterectomy is raised and concerns, in particular, thyroid cancer, renal cancer, and urinary bladder cancer. Altman et al. reported that contrary to the observation in the group without the need for surgical treatment, in cases where the benign process was the indication for the hysterectomy, a higher risk of renal cancer was noted. The mechanism of neoplastic process probably depends on catecholamines, iron metabolism, hormonal changes, and dynamic changes in the urinary tract [19-21]. Obviously, in some women hysterectomy is the only correct approach. However, many patients suffering from myomas require good alternative methods of treatment.

According to the most recent scientific reports, selective progesterone receptor modulators are the therapeutic option in these cases. Progesterone receptor has two isoforms: PR-A and PR-B. PR-A inhibits the activity of $\mathrm{PR}-\mathrm{B}$, which is regarded as a positive regulator of progesterone responsive gene. The following belong to the PR antagonists: mifepristone, telapristone, lonaprisan, asoprisnil, onapristone, and ulipristal acetate (UPA), which is a PR antagonist with partial agonistic activity. This 19-norprogesterone derivative is also a competitive antagonist of a glucocorticoid receptor. It has no activity towards oestrogen receptor, which protects against the significant reduction in oestradiol concentration that is observed in post menopause [22-25].

Progesterone is an important factor in the pathogenesis of uterine fibroids. It increases the expression of growth factors (endothelial growth factor-EGF, B-cell lymphoma 2 - Bcl-2, vascular endothelial growth factor - VEGF) and inhibits TNF- $\alpha$ (tumour necrosis factor $\alpha$ ) expression [24]. The VEGF expression in myoma tissues is higher than in normal myometrium [24, 26]. Ulipristal acetate inhibits cell proliferation and angiogenesis in uterine fibroids and also reduces collagen deposits in extracellular matrix. It results in myoma volume reduction and declines its expansion [26, 27].

Significant data concerning ulipristal acetate efficacy were provided by scientific research, especially the consecutive PEARL studies (PGL4001 - Ulipristal Acetate Efficacy Assessment in Reduction of Symptoms Due to Uterine Leiomyomata) [28-31].

In the PEARL I study the total volume of fibroids at 13 weeks was reduced in $21 \%$ and in $12 \%$, for the dose of $5 \mathrm{mg}$ and $10 \mathrm{mg}$ of ulipristal acetate, respectively. In a placebo group the volume was decreased (+3\%). Amenorrhea was noticed in $73 \%$ (5 mg of ulipristal acetate), in $82 \%$ (10 mg of ulipristal acetate), and only in $6 \%$ (placebo) [28]. PEARL II showed that UPA in doses of $5 \mathrm{mg}$ or $10 \mathrm{mg}$ is comparable to leuprolide acetate (intramuscular injection, once per month) effectiveness in uterine bleeding control and reduction of hot flushes. All treatments resulted in a size reduction of the three largest fibroids (median reduction of $36 \%$ in the group receiving $5 \mathrm{mg}, 42 \%$ in the group receiving $10 \mathrm{mg}$ ). Although in the leuprolide acetate group fibroids volume reduction was the highest (median reduction of 53\%), the maintained fibroids size reduction (for at least six months after UPA was discontinued) was observed particularly in the UPA group [29].

In 2012 the European Commission approved 5 mg of ulipristal acetate in pre-operative treatment of uterine fibroids (no longer than three months) in women of reproductive age. PEARL III and PEARL III extension (three further three-month courses of UPA along with the progestin norethindrone acetate or a placebo) showed that three-month long courses of UPA (10 mg) entailed amenorrhea in about $80 \%$ of cases and the median reduction of the three largest fibroids was $63 \%$, $67 \%$, and $72 \%$ for courses 2,3 , and 4 , respectively. In three-month follow-up the median change in their total volume (58\%) was mostly maintained. As the fourth course was completed, in more than $82 \%$ of patients $a \geq 25 \%$ reduction in volume of the three largest fibroids was noticed, and in almost $70 \%$ of women $a \geq 50 \%$ reduction was demonstrated. The reduction of median uterine volume was also observed $(-30 \%$, $-32 \%,-30 \%,-40 \%$, and $-22 \%$ for courses $2,3,4$, and three-month follow-up, respectively) [30].

PEARL IV was conducted in 11 European countries in 2012-2014 and aimed to compare $5 \mathrm{mg}$ and $10 \mathrm{mg}$ of UPA in repeated treatment. The study revealed no differences between treatment groups with regards to the volume of the three largest fibroids. Myomas volume reduction reached $54 \%$ and $58 \%$ (for $5 \mathrm{mg}$ and $10 \mathrm{mg}$ of UPA, respectively). The fibroid volume reduction was similar in both groups in respective courses (in the group receiving $5 \mathrm{mg}$ of UPA: $54 \%, 60 \%, 67 \%$, and $65 \%$ for courses 2, 3, 4, and three month follow-up, respectively; and the corresponding values in the group receiving $10 \mathrm{mg}$ of UPA were $58 \%, 64 \%, 70 \%$, and $67 \%$, respectively). No differences between treatment groups after any of the treatment courses were seen with regards to the uterine volume. There was no re-growth of fibroids observed during follow-up. Uterine bleeding intensity was well controlled in $62 \%$ of subjects ( $5 \mathrm{mg}$ of UPA) and in $73 \%$ of subjects (10 mg of UPA). No differences between treatment groups after any of the treatment courses were noticed with regards to the symptom severity. During the PEARL IV study, in $96.5 \%$ of patients the surgical procedure was not performed. In 16 subjects the reasons for the surgery was: investigator recommendation (seven subjects), patient's request (six subjects), both of them (three subjects). In six patients the main reason for the surgery was reported as 'insufficient efficacy of treatment', and in one the reason was described as poor tolerability to the treatment. In nine cases there were other reasons for the surgery [31].

In May 2015 ulipristal acetate was accepted for long-term intermittent treatment in moderate to severe 
symptoms of uterine fibroids of adult women in reproductive age. The dose of $5 \mathrm{mg}$ for three months with drug intervals is recommended. The first cycle starts in the first days of menstruation. The subsequent course should begin with the next menstruation [31, 32]. So far, the results of studies are known for the four intermittent courses.

The PEARL studies revealed no severe side effects. The most common were: hot flushes that did not lead to treatment withdrawal and disappeared spontaneously, headaches, abdominal pain, fatigue, weight gaining, breast pain, and acne. These side effects concern more than 1 per 1000 patients but less than 1 per 10 women who received UPA therapy.

It is necessary to emphasise the possibility of endometrial changes that result from the SPRMs activity. They are known as PAEC - Progesterone Modulator Receptor-Associated Endometrial Changes. For the pathologist analysing images of endometrium the information concerning UPA treatment is very important because histopathological images of PAEC are partially similar to endometrial hyperplasia and unbalanced oestrogen stimulation. In PAEC cystic glandular dilatation, apoptosis, low mitotic activity in the glands and stroma, absence of stromal breakdown, and glandular crowding are observed. These changes are reversible if UPA treatment is stopped [31-34]. Three-month therapy of UPA caused PAEC in $60 \%$ of patients [30]. In intermittent, long-term treatment (PEARL IV) PAEC was noticed less often ( $16 \%$ of patients receiving $5 \mathrm{mg}$ and $19 \%$ of patients treated with $10 \mathrm{mg}$ ) [31].

A long-term management option, which is acceptable for the patient, should rapidly control bleeding and progressively reduce the fibroid volume, and additionally it should show a good safety profile. Ulipristal acetate, the representative of SPRMs, creates an opportunity for long-term uterine fibroid treatment in women who do not accept hysterectomy or in whom this surgical procedure is contraindicated. Scientific data concerning other conservative treatment options (GnRH agonists, oral progestins, levonorgestrel IUD) are less enthusiastic in regards of drug tolerance, safety, and effectiveness in reducing uterine bleeding and leiomyoma volume. The fact that the efficacy of UPA treatment is largely maintained during the off-treatment periods cannot be ignored.

\section{Disclosure}

Authors report no conflict of interest.

\section{References}

1. Brito LG, Panobianco MS, Sabino-de-Freitas MM, et al. Uterine leiomyoma: understanding the impact of symptoms on womens' lives. Reprod Health 2014; 11: 10.

2. Bestel E, Donnez J. The potential of selective progesterone receptor modulators for the treatment of uterine fibroids. Expert Rev Endocrinol Metab 2014; 9: 79-92.
3. Khan AT, Shehmar M, Gupta JK. Uterine fibroids: current perspectives. Int J Womens Health 2014; 6: 95-114.

4. Chittawar PB, Kamath MS. Review of nonsurgical/minimally invasive treatments and open myomectomy for uterine fibroids. Curr Opin Obstet Gynecol 2015; 27: 391-397.

5. Wright RC. Hysterectomy: Past, present and future. Obstet Gynecol 1969; 33: 560-562.

6. Odejinmi F, Agarwal N, Maclaran K, Oliver R. Should we abandon all conservative treatments for uterine fibroids? The problem with leiomyosarcomas. Womens Health (Lond Engl) 2015; 11: 151-159.

7. Farquhar CM, Steiner CA. Hysterectomy rates in the United States 1990-1997. Obstet Gynecol 2002; 99: 229-234.

8. Farthmann J, Watermann D, Erbes T, et al. Functional outcome after pelvic floor reconstructive surgery with or without concomitant hysterectomy. Arch Gynecol Obstet 2015; 291: 573-577.

9. Altman D, Granath F, Cnattingius S, Falconer C. Hysterectomy and risk of stress-urinary-incontinence surgery: nationwide cohort study. Lancet 2007; 370: 1494-1499.

10. Bitti GT, Argiolas GM, Ballicu N, et al. Pelvic floor failure: MR imaging evaluation of anatomic and functional abnormalities. Radiographics 2014; 34: 429-448.

11. Sözeri-Varma G, Kalkan-Oğuzhanoğlu N, Karadağ F, Özdel O. The effect of hysterectomy and/or oophorectomy on sexual satisfaction. Climacteric 2011; 14: 275-281.

12. Atsma F, Bartelink ML, Grobbee DE, van der Schouw YT. Postmenopausal status and early menopause as independent risk factors for cardiovascular disease: a meta-analysis. Menopause 2006; 13: 265-279.

13. Ingelsson E, Lundholm C, Johansson AL, Altman D. Hysterectomy and risk of cardiovascular disease: a population-based cohort study. Eur Heart J 2011; 32: 745-750.

14. Chan CC, Ng EH, Ho PC. Ovarian changes after abdominal hysterectomy for benign conditions. J Soc Gynecol Investig 2005; 12: 54-57.

15. Farquhar CM, Sadler L, Harvey SA, Stewart AW. The association of hysterectomy and menopause: a prospective cohort study. BJOG 2005; 112: 956-962.

16. Moorman PG, Myers ER, Schildkraut JM, et al. Effect of hysterectomy with ovarian preservation on ovarian function. Obstet Gynecol 2011; 118: 1271-1279.

17. Rocca WA, Grossardt BR, Shuster LT, Stewart EA. Hysterectomy, oophorectomy, estrogen, and the risk of dementia. Neurodegener Dis 2012; 10: $175-178$.

18. Tishler TA, Raven EP, Lu PH, et al. Premenopausal hysterectomy is associated with increased brain ferritin iron. Neurobiol Aging 2012; 33 1950-1958

19. Altman D, Yin L, Johansson A, et al. Risk of renal cell carcinoma after hysterectomy. Arch Intern Med 2010; 170: 2011-2016.

20. Karami S, Daugherty SE, Purdue MP. Hysterectomy and kidney cancer risk: A meta analysis. Int J Cancer 2014; 134: 405-410.

21. Zucchetto A, Talamini R, Dal Maso L, et al. Reproductive, menstrual, and other hormone-related factors and risk of renal cell cancer. Int J Cancer 2008; 123: 2213-2216

22. Bouchard P. Selective progesterone receptor modulators: a class with multiple actions and applications in reproductive endocrinology, and gynecology. Gynecol Endocrinol 2014; 30: 683-684.

23. Donnez J, Arriagada P, Donnez O, Dolmans MM. Current management of myomas: the place of medical therapy with the advent of selective progesterone receptor modulators. Curr Opin Obstet Gynecol 2015; 27 422-431.

24. Tafi E, Scala C, Leone Roberti Maggiore U, et al. Drug safety evaluation of ulipristal acetate in the treatment of uterine fibroids. Expert Opin Drug Saf 2015; 14: 965-977

25. Murdoch M, Roberts M. Selective progesterone receptor modulators and their use within gynaecology. Obstet Gynaecol 2014; 16: 46-50.

26. Maruo T, Ohara N, Yoshida S, et al. Lessons learned from the preclinical drug discovery of asoprisnil and ulipristal for non-surgical treatment of uterine leiomyomas. Expert Opin Drug Discov 2011; 6: 897-911.

27. Tal R, Segars JH. The role of angiogenic factors in fibroid pathogenesis: potential implications for future therapy. Hum Reprod Update 2014; 20 : 194-216.

28. Donnez J, Tatarchuk TF, Bouchard P, et al.; PEARL I Study Group. Ulipristal acetate versus placebo for fibroid treatment before surgery. $N$ Engl J Med 2012; 366: 409-420. 
29. Donnez J, Tomaszewski J, Vázquez F, et al.; PEARL II Study Group. Ulipristal acetate versus leuprolide acetate for uterine fibroids. $N$ Eng J Med 2012; 366: 421-432.

30. Donnez J, Vázquez F, Tomaszewski J, et al.; PEARL III and PEARL III Extension Study Group. Long-term treatment of uterine fibroids with ulipristal acetate. Fertil Steril 2014; 101: 1565-1573.

31. Donnez J, Hudecek R, Donnez O, et al. Efficacy and safety of repeated use of ulipristal acetate in uterine fibroids. Fertil Steril 2015; 103: 519527.

32. Latta E, Lefebvre G, Ferenczy A. Selective progesterone receptor modulators: Clinical roles and effects on endometrial histology. Canadian J Pathol 2015; 2 Suppl 2: s4-24.

33. Mutter GL, Bergeron C, Deligdisch L, et al. The spectrum of endometrial pathology induced by progesterone receptor modulators. Mod Pathol 2008; 21: 591-598.

34. Ioffe OB, Zaino RJ, Mutter GL. Endometrial changes from short-term therapy with CDB-4124, a selective progesterone receptor modulator Mod Pathol 2009; 22: 450-459. 